\title{
Choline deficiency-induced apoptosis in PC 12 cells is associated with diminished membrane phosphatidylcholine and sphingomyelin, accumulation of ceramide and diacylglycerol, and activation of a caspase
}

\author{
CHI-LIANG E. YEN, MEI-HENG MAR, AND STEVEN H. ZEISEL ${ }^{1}$ \\ Department of Nutrition, School of Public Health and School of Medicine, The U niversity of North \\ Carolina at Chapel Hill, Chapel Hill, North Carolina 27599-7400, USA
}

ABSTRACT It is not well appreciated that nutritional status can modulate apoptosis, a process that eliminates unwanted or damaged cells. Choline is an essential nutrient, and its absence induces apoptosis. When PC 12 cells were cultivated in a choline-free medium, apoptosis was induced $(27.4 \%$ of cells apoptotic at $72 \mathrm{~h}$ as compared to $4.4 \%$ in control medium). In choline-free medium at $72 \mathrm{~h}$, there was a 49\% decrease in phosphatidylcholine concentration $(\mathbf{P}<0.01)$ and a 34\% decrease in sphingomyelin concentration $(\mathbf{P}<\mathbf{0 . 0 1})$; however, there was no change in phosphatidylethanolamine concentration. Before detecting increased apoptosis in choline-deficient cells, we measured a significant increase in ceramide ( $218 \%$ control) and diacyglycerol ( $155 \%$ control) concentrations. The addition of a cell-permeable ceramide to cells in control medium induced apoptosis; however, adding a cell-permeable diacyglycerol did not induce apoptosis. C aspase is a common mediator of apoptosis, and choline deficiency-induced apoptosis was prevented completely by replacing choline or adding a caspase inhibitor into the medium within $48 \mathrm{~h}$ of initial choline deprivation. In those cells rescued by replacing choline at $36 \mathrm{~h}$, the concentrations of phosphatidylcholine, sphingomyelin, ceramide, and diacyglycerol returned to levels of control cells. In those cells rescued by adding a caspase inhibitor at $36 \mathrm{~h}$, the concentrations of sphingomyelin and ceramide returned to control levels, but the concentrations of phosphatidylcholine and diacyglycerol did not return to normal. We propose that availability of dietary factors (choline in this model) can modulate apoptosis. Mechanisms that we identify using this model may help us to explain why dietary choline influences brain development.-Yen, C. $L$. E., Mar, M.H., Zeisel, S. H. Choline deficiency-induced apoptosis in PC 12 cells is associated with diminished membrane phosphatidylcholine and sphingomyelin, accumulation of ceramide and diacylglycerol, and activation of a caspase. FASE B J. 13, 135- 142 (1999)
Key Words: CDP-choline. PtdCho. sphingomyelin ' DAG . DNA ladders

APOPTOSIS IS AN intrinsic cell suicide program that eliminates unwanted or damaged cells ( 1 ). In addition to its essential role in embryogenesis, a number of significant human diseases, including cancer, neurodegenerative diseases, and AIDS, are associated with abnormally regulated apoptosis (2). Little attention has been given to the role of nutrients in regulating apoptosis. As an example of nutrient-apoptosis interactions, we report the effects of the nutrient choline on the induction and progression of apoptosis.

Apoptosis has been defined morphologically (3). Cells undergoing apoptosis are recognized by characteristic features such as cell shrinkage and nuclear fragmentation $(4,5)$. When DNA is resolved by electrophoresis, apoptotic cells often show 'DNA laddering' that results from internucleosomal DNA cleavage, which is considered the hallmark of apoptosis (6). Apoptosis proceeds in three phases: induction, signal cascade modulation, and commitment with activation of an execution pathway, which may involve a family of cysteine proteases (caspases) (7) and an endonuclease (8).

Choline is an important nutrient for the normal function of all cells, and the Institute of Nutrition of the National Academy of Science recently concluded that dietary choline is essential for humans (9). Choline is the major source of methyl groups in the diet, as well as a major component of phospholipids and a precursor of the neurotransmitter acetylcholine (10). Choline deficiency induces apoptosis both in vitro and in whole animals $(11,12)$. However, the mechanisms for choline deficiency-induced apopto-

\footnotetext{
${ }^{1}$ Correspondence: Department of Nutrition, School of Public Health and School of Medicine, The University of North Carolina at Chapel Hill, CB \#7400, Chapel Hill, NC 275997400, USA. E-mail: steven_zeisel@unc.edu
} 
sis are not known. It is unlikely that methyl deficiency is the critical mechanism since apoptosis is induced in choline-deficient cells even when methyl group availability is more than adequate (13).

The choline-containing phospholipids phosphatidylcholine (PtdCho) ${ }^{2}$ and sphingomyelin (SM) are not only the major structural components of cell membranes but are also reservoirs of the lipid second messengers diacylglycerol (DAG) and ceramide (Cer) (14). The metabolic pathways of these cholinephospholipids and second messengers are interrelated. For example, in the cytidine diphosphocholine (CDP-choline) pathway, the predominant pathway for PtdCho biosynthesis, choline is converted to CDPcholine, which combines with DAG and generates PtdCho (10). In addition, the last step of SM biosynthesis involves the transfer of a phosphocholine head group from PtdCho to Cer (15).

Studies over the past few years have established that the levels and/ or balance between lipid second messengers, including DAG and Cer generated from hydrolysis of PtdCho and SM, modulate signal transduction pathways, including those regulating cell growth, differentiation, and apoptosis $(8,16,17)$. Since DAG and Cer are both synthesis intermediates and breakdown products of choline phospholipids, we hypothesized that deprivation of choline perturbs choline phospholipid metabolism, altering lipid second messenger levels and inducing apoptosis.

Choline deficiency is of special interest with regard to neurons because, in the rat, supplemental choline during pregnancy results in lifelong enhancement of hippocampal function in offspring (18-22), and the rate of apoptosis in fetal hippocampus is inversely related to the dietary choline intake of the rat dam (12). In this paper we explore the mechanisms underlying choline deficiency-induced apoptosis using a 'neuronlike' cell line, PC12, derived from a rat pheochromocytoma.

\section{MATERIALS AND METHODS}

\section{Cell culture}

PC12 cells were the kind gift of Dr. J. P. O'Bryan at the University of N orth Carolina at Chapel $\mathrm{H}$ ill. The cells were maintained in DMEM-H medium (Life Technologies, Grand Island, N.Y.) containing $10 \%$ horse serum (Hyclone, Logan, Utah) and $5 \%$ calf serum (JRH Biosciences, Lenexa, Kans.). Because choline and PtdCho are present in sera, a chemically defined medium was used for both experimental and control groups of cells. Two days before the experiments, cells were

\footnotetext{
${ }^{2}$ Abbreviations: Cer, ceramide; CDP-choline, cytidine diphosphocholine; DAG, diacylglycerol; ET-18-O $\mathrm{CH}_{3}, 1-0$-octadecyl-2-methyl-rac-glycero-3-phosphocholine; PtdCho, phosphatidylcholine; SM, sphingomyelin; TLC, thin-layer chromatography.
}

shifted into this defined medium consisting of DMEM/ F12 (American Biorganics, Niagara Falls, N.Y.) , 100 mg/ I transferrin (Intergen, Purchase, N.Y.). $10 \mathrm{mg} / \mathrm{I}$ insulin (Sigma, St. Louis, Mo.), $0.378 \mathrm{mg} /$ I triiodothyronine (Sigma), $0.4 \mathrm{mg} /$ I L-thyroxine (Sigma), $0.039 \mathrm{mg} /$ I selenium (Sigma), $16.6 \mathrm{mg} /$ I putrescine (Sigma), $0.62 \mathrm{mg} /$ I progesterone (Sigma), 17.24 $\mathrm{mg} / \mathrm{I}$ methionine (Sigma), $11.5 \mu \mathrm{M}$ bovine serum albumin (Intergen), $20 \mu \mathrm{M}$ oleate (Sigma), and $7.2 \mu \mathrm{M}$ linoleate (Sigma). Unless specified, PC12 cells were seeded at $5 \times 10^{5}$ per $100 \mathrm{~mm}$ dish (Falcon, Franklin Lake, N.J.) in medium containing $10 \%$ horse serum and $5 \%$ calf serum for $24 \mathrm{~h}$. The medium was replaced with the defined medium containing 70 $\mu \mathrm{M}$ choline for $48 \mathrm{~h}$. Cells were then incubated in defined medium with $70 \mu \mathrm{M}$ choline (control) or without choline for specified periods of time.

\section{Determination of apoptosis}

\section{M orphological analysis}

Apoptosis was assessed in both attached and detached cells, which were collected and deposited onto glass slides using a cytocentrifuge. Cells were then fixed with methanol, stained with hematoxylin (Fisher, Fair Lawn, N.J.), and mounted with Permount (Fisher). Slides were examined under a light microscope and the percentage of apoptotic cells was determined by counting at least 200 cells in four replicate cultures per treatment. Cells with fragmented nuclei (multiple, small hematoxylinophilic bodies) were defined as apoptotic $(4,23)$.

\section{DNA fragmentation (DNA ladders)}

Samples ( $\approx 2 \times 10^{6}$ cells) were lysed in $1 \mathrm{ml}$ lysis buffer containing $50 \mathrm{mM}$ Tris ( $\mathrm{pH}$ 7.4), $10 \mathrm{mM}$ EDTA, 0.5\% N-laurosarcosine (Sigma) and incubated for $3 \mathrm{~h}$ with $0.5 \mathrm{mg} / \mathrm{ml}$ protease $\mathrm{K}$ (Boehringer Mannheim, Indianapolis, Ind.) at $65^{\circ} \mathrm{C}$. Cells were then incubated for $1 \mathrm{~h}$ with $24 \mathrm{U} / \mathrm{ml}$ DNase-free RNase (Boehringer Mannheim) at $50^{\circ} \mathrm{C}$. After extraction with an equal volume of phenol/chloroform/isoamylalcohol $(25: 24: 1, v / v)$ and precipitation with 2 volumes of absolute ethanol, the DNA was resuspended in $100 \mu 10 \mathrm{mM}$ Tris buffer ( $\mathrm{pH}$ 7.4) containing $1 \mathrm{mM}$ EDTA. The DNA concentration was determined by measurement of optical density at $260 \mathrm{~nm}$. Ten micrograms of DNA were subjected to electrophoresis on a $1.2 \%$ agarose gel at $100 \mathrm{~V}$ for $2 \mathrm{~h}$. DNA was visualized and photographed under UV light after ethidium bromide staining.

\section{Biochemical determinations}

Samples were collected at various time intervals after cells had been treated with experimental media. To ensure an equal number of cells in both the experimental and control groups, DNA was measured as a basis for normalization using the fluorometric method described by Labarca and Paigen (24). To determine whether choline deficiency altered phospholipid levels, cellular phospholipids were assayed after total lipids were extracted using the procedure described by Bligh and Dyer (25). PtdCho (Rf, 0.37), phosphatidylethanolamine (Rf, 0.43 ), and SM (Rf, 0.25) were separated by thin-layer chromatography (TLC, chloroform/ methanol/ 40\% methylamine, $60: 20: 5 \mathrm{v} / \mathrm{v}$ ) and quantitated with a phosphorus assay using both inorganic phosphorus (phosphorus standard solution: Sigma) and authentic phospholipidsasstandards (26). Similar results were obtained with either standard. Choline, phosphocholine, and glycerophosphocholine in cell extracts were separated using a high-performance liquid chromatography procedure after addition of ${ }^{14} \mathrm{C}$ labeled internal standards. 
Also, $\left[{ }^{2} \mathrm{H}\right.$-methyl]-labeled internal standards of each metabolite were added to permit correction for recovery after analysis of choline moiety by a gas chromatography/ mass spectrometry assay (27).

To determine the effect of choline deprivation on intracellular levels of Cer and DAG, these lipids were simultaneously extracted and assayed using the radioenzymatic method described by Preiss et al. (28). Briefly, cells were fixed on the culture dish with $1.5 \mathrm{ml}$ methanol, scraped off the plate, and transferred into a $15 \mathrm{ml}$ centrifuge tube (Falcon). After adding $3 \mathrm{ml}$ of chloroform, the samples were mixed and incubated overnight at $-20^{\circ} \mathrm{C}$. Cell debris was pelleted by centrifugation, further extracted twice with $1 \mathrm{ml}$ chloroform/ methanol ( $1: 1$ and 1:2 sequentially), and extracts were combined. We added $1 \mathrm{ml} \mathrm{CHCl}_{3}$ and $1 \mathrm{ml} \mathrm{H}_{2} \mathrm{O}$, and the organic phase was separated and dried under $\mathrm{N}_{2}$. Cer and DAG were then converted to ceramide-1-[ $\left.{ }^{32} \mathrm{P}\right]$ phosphate and phosphatidic acid by Escherichia coli diacylglycerol kinase (CalBiochem, La Jolla, Calif.) and [ $\gamma^{-32}$ ] ATP. The labeled lipids were separated by TLC (Baker, Phillipsburg, N.J., Baker Si250 PA silica gel, chloroform/ pyridine/ 88\% formic acid, 60:30:7, v/ v). Spots corresponding to authentic ceramide-1-phosphate and phosphatidic acid standards were counted using a radiometric imaging scanner (Bioscan System 200, Washington, D.C.) and quantified using a standard curve of known amounts of Cer and DAG.

\section{Exogenous cell-permeable ceramide and caspase inhibitor experiments}

We tested whether added lipid second messengers (cell-permeable Cer or DAG analog) could induce apoptosis in choline-sufficient cells. PC12 cells cultivated in the control medium were exposed to various concentration of C6-Cer $(0.5$, 1, 5 10, $20 \mu \mathrm{M}$; Sigma) or $20 \mu \mathrm{M}$ dioctanoylglycerol (Sigma). Cells exposed to vehicle (DMSO) only were included as control. Cells were harvested $24 \mathrm{~h}$ later and apoptosis was assessed by cell morphology.

We also determined whether the caspase inhibitor, Z-VADfmk (CalBiochem), prevented apoptosis induced by either choline deficiency or ceramide. PC12 cells were grown in defined medium containing 1) $70 \mu \mathrm{M}$ choline (control); 2) 0 $\mu \mathrm{M}$ choline; 3) $0 \mu \mathrm{M}$ choline plus $100 \mu \mathrm{M}$ Z-VAD-fmk; 4) 20 $\mu \mathrm{M}$ C2-ceramide and $70 \mu \mathrm{M}$ choline; and 5) $20 \mu \mathrm{M}$ C2-ceramide and $70 \mu \mathrm{M}$ choline plus $100 \mu \mathrm{M}$ Z-VAD-fmk. Cells were harvested either $72(1-3)$ or $24 \mathrm{~h}(5,6)$ later. Apoptosis was assessed by cell morphology.

\section{Cell rescue experiments}

We determined whether there was a specific time period during which choline-deprived cells could be rescued from committing to apoptosis. PC12 cellswere incubated in the cholinefree medium for $72 \mathrm{~h}$. These cells were divided into two major groups: one for choline replacement and one for caspase inhibition. Each group was then divided into six subgroups. Choline was added to the choline replacement subgroups at a final concentration of $70 \mu \mathrm{M}$ after the times indicated ( 0 , $24,36,48,60$, or $72 \mathrm{~h}$ ). Therefore, the subgroup receiving choline at $0 \mathrm{~h}$ always grew in choline-sufficient control medium and the $72 \mathrm{~h}$ subgroup was choline deprived throughout the entire experimental period.

In the caspase inhibition subgroups, $100 \mu \mathrm{M}$ Z-VAD-fmk was added at the times indicated $(0,24,36,48,60$, or $72 \mathrm{~h})$. Cells were harvested $72 \mathrm{~h}$ after switching to choline-free medium. Apoptosis was assessed by cell morphology. DNA fragmentation was also assayed to confirm the presence of apoptosis.
To determine the lipid profiles of rescued cells, PC12 cells were incubated in the choline-free medium for $72 \mathrm{~h}$. Choline or Z-VAD-fmk was added at $36 \mathrm{~h}$ after initial choline deprivation to a final concentration of 70 or $100 \mu \mathrm{M}$, respectively. Cells grown in choline-sufficient $(70 \mu \mathrm{M})$ and choline-deficient $(0 \mu \mathrm{M})$ medium were also included as control. Cellswere harvested $72 \mathrm{~h}$ after switching to choline-free medium. The intracellular levels of PtdCho, SM, Cer, and DAG were assayed as described above.

\section{Statistics}

We used one-way analysis of variance, followed by the Dunnett's critical difference test to determine statistical significance between the treatment groups and control (JMP Version 2, SAS, 1989).

\section{RESULTS}

When PC12 cells were cultivated in a chemically defined medium without choline cells stopped growing and/ or started dying after $48 \mathrm{~h}$ (data not shown). The percentage of cells that were apoptotic (quantified based on morphologic characteristics) in choline-free medium was significantly greater than in control medium ( $70 \mu \mathrm{M}$ choline) after $54 \mathrm{~h}$ of choline deprivation ( $5.2 \pm 0.3 \%$ vs. $1.6 \pm 0.6 \%, \mathrm{P}<0.05$; after 72 h, $27.4 \pm 0.6 \%$ vs. $4.4 \pm 1.1 \%, P<0.01$; Fig. 1 ). The occurrence of apoptosis was also confirmed by presence of DNA ladders (Fig. 1, inset).

Choline and its metabolites were measured to verify the choline status of these cells. At $72 \mathrm{~h}$ watersoluble choline metabolites, including choline, phos-

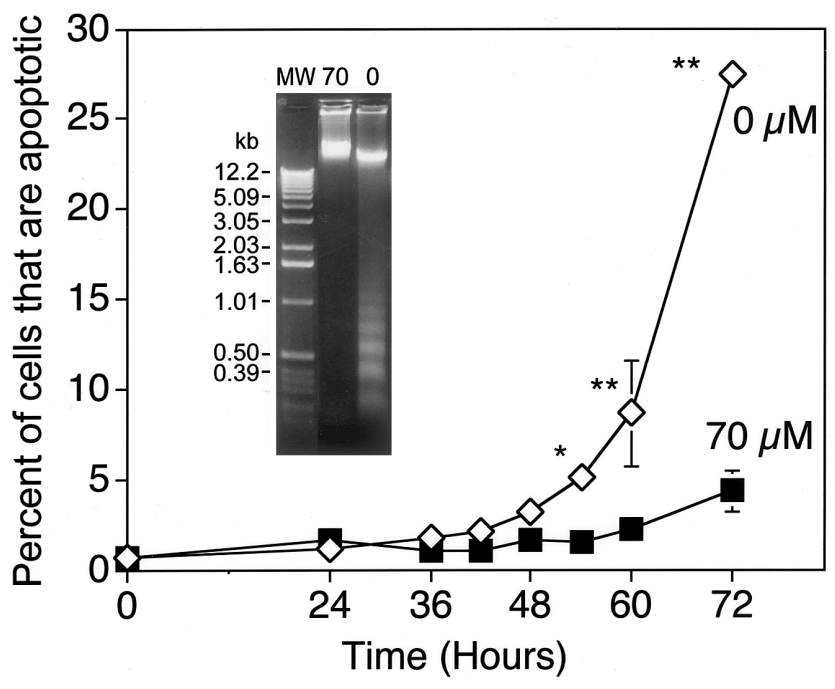

Figure 1. Choline deficiency induces apoptosis. PC12 cells in defined medium containing $70 \mu \mathrm{M}$ or $0 \mu \mathrm{M}$ choline were harvested at the times indicated. Apoptosis was assessed by cell morphology. Data represent means $\pm \mathrm{SE}, \mathrm{n}=4$ / point, $* * \mathrm{P}<$ 0.01 different from control. When error bars are not visible they were smaller than the symbol size. The presence of apoptosis was also confirmed by DNA fragmentation (inset), MW $=$ molecular weight markers, $70=$ control, $0=$ choline-deficient. 

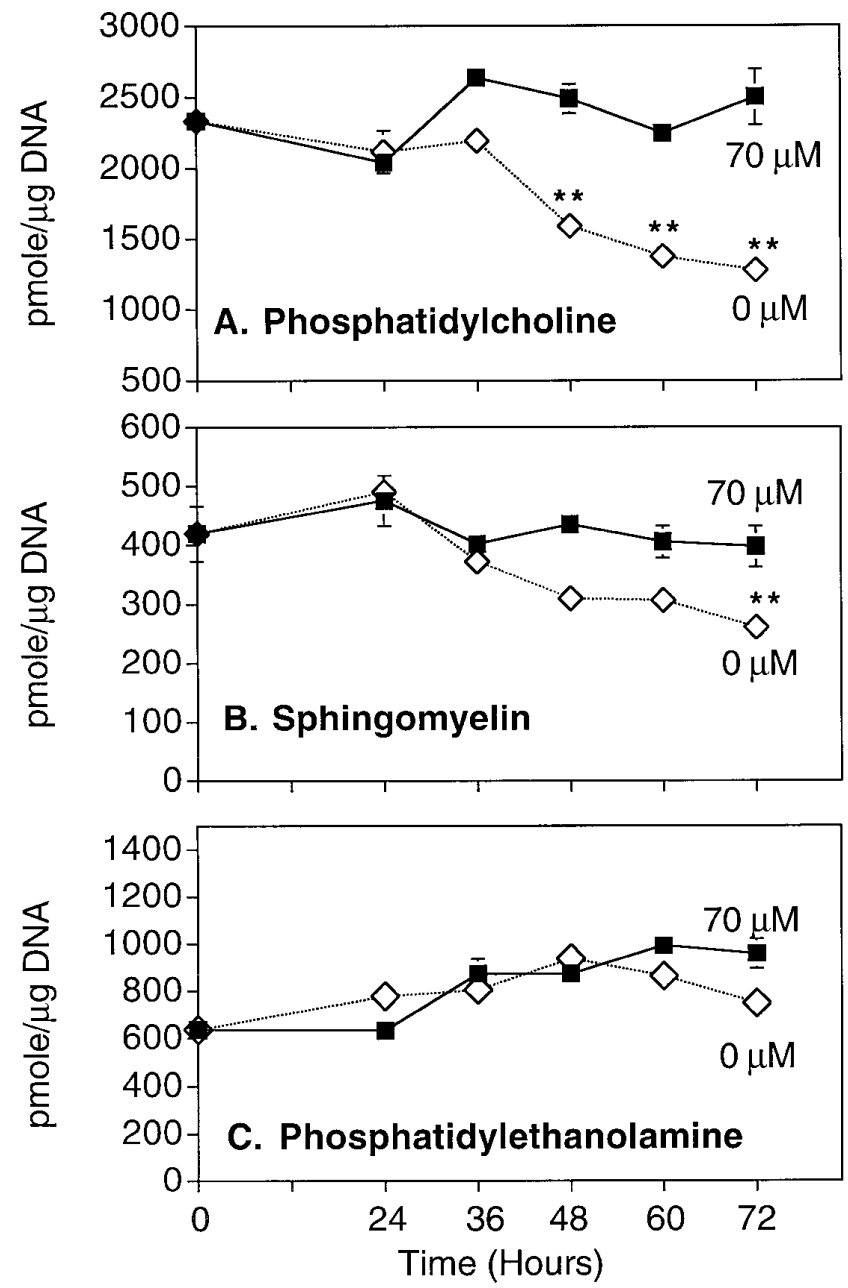

Figure 2. Phosphatidylcholine and sphingomyelin concentrations decrease upon choline deprivation. PC12 cells in defined medium containing $70 \mu \mathrm{M}$ or $0 \mu \mathrm{M}$ choline were harvested at the indicated times. Phospholipids were measured by thin-layer chromatography and a colorimetric assay for phosphorus. Data represent means $\pm S E, n=4 /$ point, $* * P$ $<0.01$ different from control. When error barsare not visible, they were smaller than the symbol size.

phocholine, and glycerophosphocholine, dropped below detectable range (less than $5 \mathrm{pmol} / \mu \mathrm{g}$ DNA) in choline-deprived cells as compared to $102 \pm 17$ pmol choline/ $\mu \mathrm{g}$ DNA, $653.2 \pm 14.8$ pmol phosphocholine/ $\mu \mathrm{g} D N A$, and $57.6 \pm 6.6$ pmol glycerophosphocholine/ $\mu \mathrm{g}$ DNA in control cells. DNA per cell did not change significantly with treatment ( $14 \pm 2 \mu \mathrm{g}$ DNA per $10^{6}$ cells in choline-deficient cells vs. $12 \pm 1 \mu \mathrm{g}$ DN A per $10^{6}$ cells in controls; $\mathrm{P}=0.4017$ )

Before an increase in apoptosis, PtdCho concentrations decreased when cells were cultivated in choline-free medium. (At $48 \mathrm{~h}$ there was a 38\% decrease; $\mathrm{P}<0.01$; Fig. 2A.) Itsconcentrations remained low for the rest of the experimental period (decreased by $49 \%$ at $72 \mathrm{~h} ; \mathrm{P}<0.01$ ). SM concentrations also decreased, with values at $72 \mathrm{~h}$ being $34 \%$ lower in choline-deficient cells than in controls $(\mathrm{P}<0.01$; Fig. $2 \mathrm{~B})$, although the difference was not statistically signifi- cant until $72 \mathrm{~h}$ of treatment. Phosphatidylethanolamine concentration (Fig. 2C) did not decrease in choline-deficient cells as compared with control cells.

We measured a significant increase in Cer $(218 \%$ of control) and DAG ( $155 \%$ of control) concentrations (Fig. 3) at $48 \mathrm{~h}$ after choline deprivation. Concentrations of Cer and DAG in choline-deficient cells continued to rise throughout the experiment. At 72 $\mathrm{h}$ Cer mass in choline-deficient cells increased to $316 \%$ of control and DAG mass increased to $230 \%$ of control. Although the percentage changes in Cer and DAG after choline deprivation are more dramatic than those seen in phospholipids, the differences in mass were actually smaller than those observed in phospholipids. This was due to the much larger pool of phospholipids in cells as compared to Cer or DAG.

Cer per se should induce apoptosis if it mediates choline deficiency-induced apoptosis. Figure $\mathbf{4}$ shows that C6-Cer, a cell-permeable Cer analog, induced apoptosis in PC12 cells and the response was dose dependent. When choline-sufficient PC12 cells were exposed to $20 \mu \mathrm{M}$ C6-Cer for $24 \mathrm{~h}, 36.8 \pm 7.5 \%$ of cells were apoptotic as compared to $0.9 \pm 0.2 \%$ in controls exposed to vehicle (DMSO; $\mathrm{P}<0.01$ ). Exogenous C2-Cer, another cell-permeable analog, also
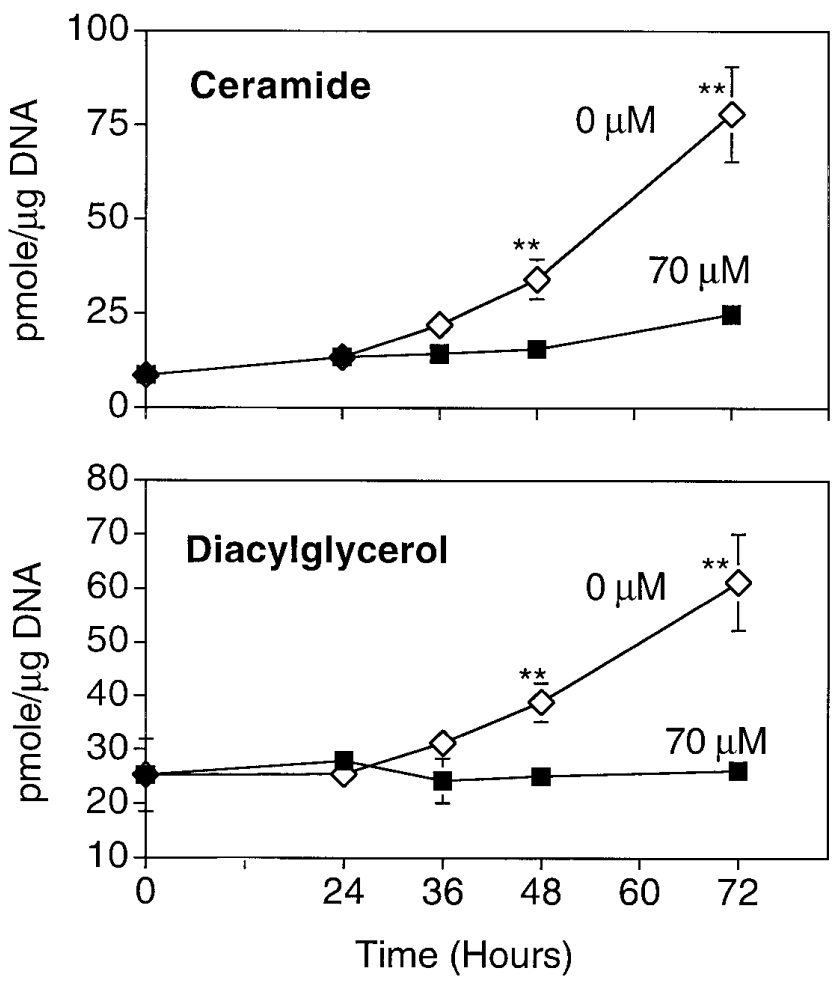

Figure 3. Ceramide and diacylglycerol rise after choline deprivation. PC12 cells in defined medium containing $70 \mu \mathrm{M}$ or $0 \mu \mathrm{M}$ choline were harvested at indicated times. Ceramide and diacylglycerol were measured by a radioenzymatic assay. Data represent means $\pm S E, n=8 /$ point, $* P<0.01$ different from control. When error bars are not visible, they were smaller than the symbol size. 


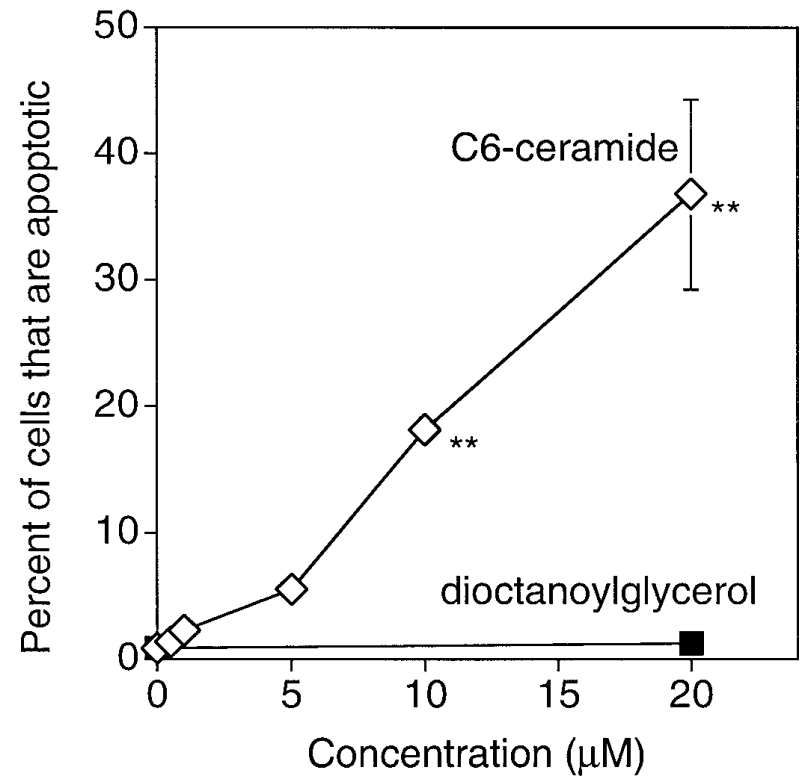

Figure 4. Added ceramide, but not diacylglycerol, inducesapoptosis. PC12 cells were grown as described in Materials and Methods and then switched to defined medium containing various amount of C6-ceramide $(0,0.5,1,5,10$, and $20 \mu \mathrm{M})$ or $20 \mu \mathrm{M}$ dioctanoylglycerol. Cells were harvested $24 \mathrm{~h}$ later. Apoptosis was assessed by morphology of cells. Data represent means $\pm \mathrm{SE}, \mathrm{n}=4 /$ point, $* * \mathrm{P}<0.01$ different from control ( $70 \mu \mathrm{M}$ choline).

caused a similar effect $(31.2 \pm 2.3 \%$ apoptotic in 20 $\mu \mathrm{M}$ Cer-treated group vs. $2.3 \pm 0.3 \%$ in control group; $\mathrm{P}<0.01)$. A cell-permeable DAG $(20 \mu \mathrm{M}$ dioctanoylgylcerol) did not induce more apoptosis ( $1.25 \pm 0.4 \%$ of cells were apoptotic) than was present in controls.

Caspases, a family of the interleukin $1 \beta$-converting, enzyme-like cysteine proteases, are implicated in apoptotic signaling (7). The caspase inhibitor Z-VADfmk prevents Cer-induced apoptosis (29, 30). Figure 5 shows that inhibition of caspase proteases using ZVAD-fmk blocked both choline deficiency- and ceramide-induced apoptosis in PC12 cells.

To estimate the exposure time necessary for choline deprivation to induce apoptosis, we determined the latest time point at which PC12 cells could be rescued from choline-free medium before they were committed to die. When PC12 cells were incubated in choline-free medium for $72 \mathrm{~h}$, replacing choline into the culture medium prevented apoptosis completely as long as it was added sooner than $48 \mathrm{~h}$ after initial choline deprivation. Replacement at $48 \mathrm{~h}$ and thereafter did not rescue all the cells. The longer the exposure to choline deficiency, the greater the number of cells that were committed to apoptosis (Fig. 6) . For example, in the subgroup where choline was replaced at $60 \mathrm{~h}, 26 \%$ of cells were apoptotic at $72 \mathrm{~h}$ as compared with $4.2 \%$ in choline-sufficient controls after the same time interval. When choline was replaced at $36 \mathrm{~h}$ the rates of apoptosis at $72 \mathrm{~h}$ were the same as in controls. Similar results were observed in an experiment where choline-deficient cells were rescued by adding the caspase inhibitor Z-VAD-fmk ( Fig. $6)$. We then determined whether the rescued cells returned their lipid profiles to the control levels. We found that, at $72 \mathrm{~h}$, the concentrations of PtdCho, $\mathrm{SM}, \mathrm{Cer}$, and DAG returned to normal levels in choline-deprived cells rescued by replacing choline at 36 h. Conversely, only Cer and SM, but not PtdCho or $D A G$, levels were corrected in those cells rescued by adding Z-VAD-fmk (Fig. 7).

\section{DISCUSSION}

We report that choline deficiency-induced apoptosis in PC12 cells was preceded by decreased PtdCho and SM concentrations and by increased Cer and DAG concentrations. Exogenous cell-permeable Cer, but not added DAG, induced apoptosis in PC12 cells. A caspase inhibitor, Z-VAD-fmk, blocked both choline deficiency- and exogenous Cer-induced apoptosis, and there was a critical time period when choline deficiency-induced apoptosis could be aborted by replacing choline or adding a caspase inhibitor. PtdCho, DAG, SM, and Cer levels returned to normal in choline-deprived cells rescued by replacing choline whereas only Cer and SM levels returned to normal in cells rescued by Z-VAD-fmk.

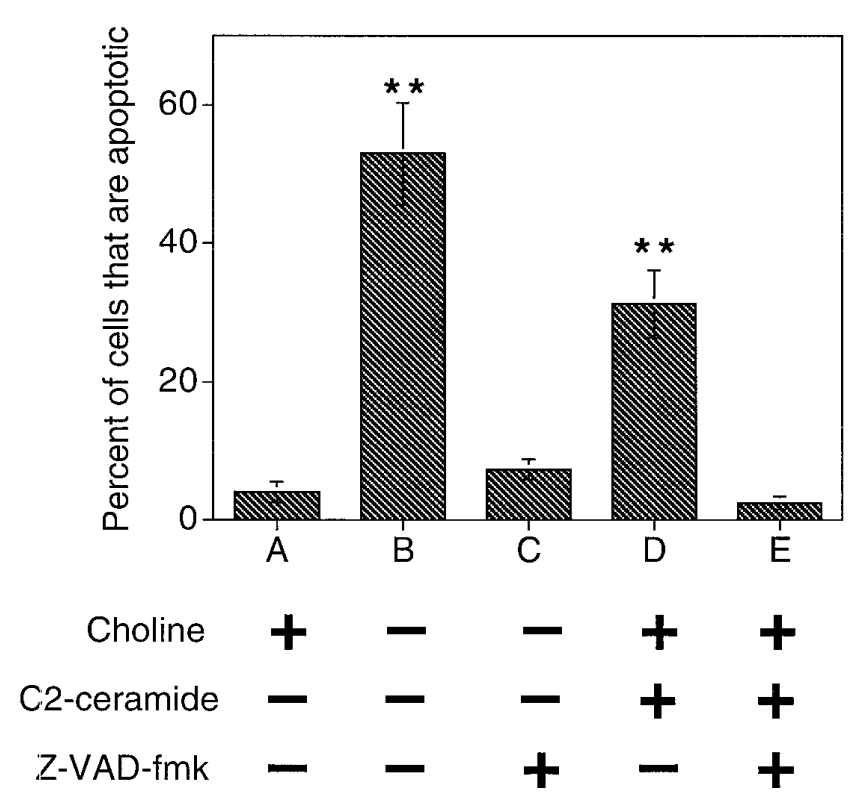

Figure 5. A caspase inhibitor suppresses both choline deficiency-induced and ceramide-induced apoptosis. PC12 cells were grown as described in experimental procedure and then switched to defined medium containing A) $70 \mu \mathrm{M}$ choline; B) $0 \mu \mathrm{M}$ choline; C) $0 \mu \mathrm{M}$ choline plus $100 \mu \mathrm{M}$ Z-VAD-fmk; D) $20 \mu \mathrm{M}$ C2-ceramide and $70 \mu \mathrm{M}$ choline; and E) $20 \mu \mathrm{M} \mathrm{C2-}$ ceramide and $70 \mu \mathrm{M}$ choline plus $100 \mu \mathrm{M}$ Z-VAD-fmk. Cells were harvested either $72(A-C)$ or $24 \mathrm{~h}(\mathrm{D}, \mathrm{E})$ later. Apoptosis was assessed by morphology of cells. Data represent means \pm $\mathrm{SE}, \mathrm{n}=4 /$ point, $* * \mathrm{P}<0.01$ different from control $(70 \mu \mathrm{M}$ choline). 
Choline is particularly important during the prenatal period because dietary availability of this nutrient influences brain function. When rat pups received choline supplements [in utero during days 12-17 of gestation (E12-17)] their brain function changed, resulting in enhanced long-term potentiation in hippocampus (31) and lifelong enhancement of memory and attention (18-22, 32). These effects of choline on brain function may be mediated by changes in apoptosis in brain; we reported that the rate of apoptosis in fetal hippocampus was inversely related to the dietary choline intake of the rat dam (12). Our studies of PC12 cells shed some light on the mechanisms that might be responsible for dietary modulation of apoptosis in brain.

We found that apoptosis in choline-deficient PC12 cells occurred after a decrease in cellular PtdCho concentration and after increases in Cer and DAG concentrations. These observations are consistent with the hypothesis that choline deficiency induces apoptosis by perturbing the metabolism of choline phospholipids and related second messengers.

Intracellular PtdCho concentration has been suggested as a modulator of cell growth and death. PtdCho is essential for normal progression through the cell cycle; its biosynthesis and degradation are coordinated with cell cycle progression (33). Cellsincapable of PtdCho synthesis by the CDP-choline pathway die by apoptosis (29) . Exposure to 1-0-octadecyl-2methyl-rac-glycero-3-phosphocholine $\left(\mathrm{ET}-18-\mathrm{OCH}_{3}\right)$, a PtdCho synthesis inhibitor, led to cell cycle arrest as well as apoptosis (34). When lysophosphatidylcholine was added to restore PtdCho synthesis, ET-18-0 $\mathrm{CH}_{3-}$ induced apoptosis was prevented, but its growth arrest effect remained (35). We previously reported that the rate of apoptosis was inversely correlated with intracellular PtdCho concentration in rat hepatocytes cultivated in various concentrations of choline (36). We now report that PtdCho concentrations drop before induction of apoptosis in choline-deficient PC12 cells. Therefore, decrease in PtdCho level may be an early event in choline deficiency-induced apoptosis.

DAG can be formed by phospholipase C-mediated hydrolysis of PtdCho (17) or it can accumulate when not utilized to form PtdCho because of the lack of choline moiety. DAG, an activator of protein kinase $C(17)$, is generally associated with mitogenic signals $(17,37)$, and it attenuates ceramide-induced apoptosis $(38,39)$. H owever, DAG also activates acidic sphingomyelinase $(40,41)$ and contributes to the generation of ceramide originated by Fas/ Apol (CD95) (42). Our observations that exogenous DAG did not alter apoptosis and that choline-deficient cells rescued by Z-VAD-fmk still contained high concentrations of DAG suggest that DAG is not the critical messenger responsible for inducing apoptosis in the PC12 cells. We have previously observed elevated DAG concentrations in livers from choline-deficient

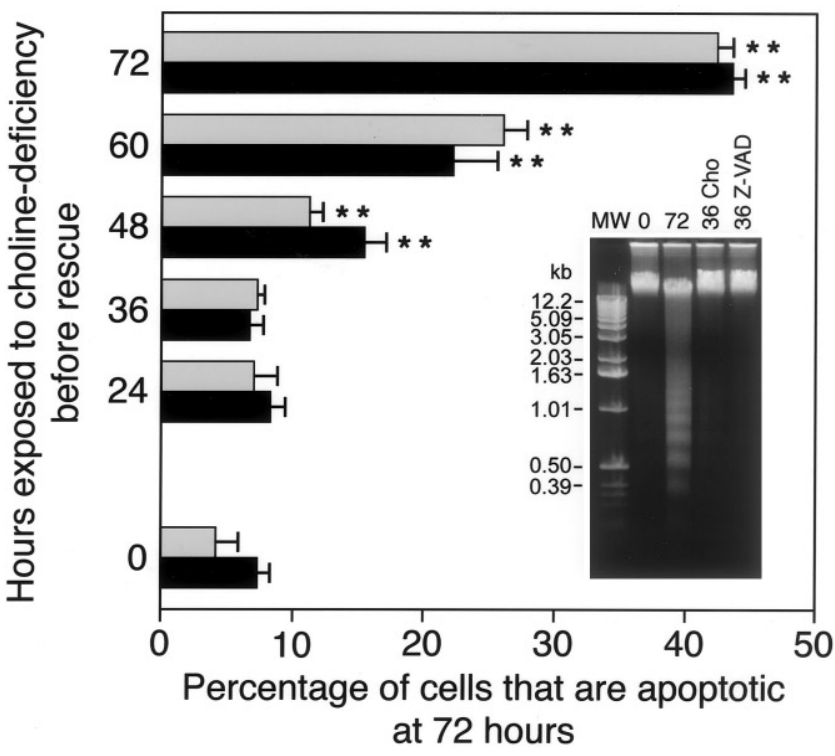

Figure 6. Choline-deprived cells can be rescued from apoptosis by replacing choline or adding Z-VAD-fmk within $48 \mathrm{~h}$. PC12 cells were grown in defined medium without choline for $72 \mathrm{~h}$ as described. Choline or Z-VAD-fmk was added to a final concentration of 70 or $100 \mu \mathrm{M}$, respectively, at indicated times. Cells were harvested $72 \mathrm{~h}$ after switching to choline-free medium. Apoptosis was assessed by cell morphology. Data represent means $\pm S E, n=4 /$ point, $* * P<0.01$ different from control (rescue agent added at time 0 ). Stippled bars $=$ choline replaced; Solid bars = Z-VAD-fmk added. Inset: Apoptosis in cells at $72 \mathrm{~h}$ was confirmed by electrophoresis of DNA. Agarose gel electrophoresis of DNA from some representative samples treated as described for main figure. Lane 1: MW, molecular weight markers; lane 2: 0 , rescue with $70 \mu \mathrm{M}$ choline at $0 \mathrm{~h}$; lane 3: 72, no rescue; lane 4: 36 Cho, rescue with $70 \mu \mathrm{M}$ choline at $36 \mathrm{~h}$; lane 5: $36 \mathrm{Z}-\mathrm{VAD}$, rescue with $100 \mu \mathrm{M}$ ZVAD-fmk at $36 \mathrm{~h}$.

rats, with concomitant activation of protein kinase $C$ (43). Perhaps DAG has a similar effect in PC12 cells.

We suggest that Cer mediates choline deficiencyinduced apoptosis based on our observations that 1) Cer concentrations increased before increase in apoptosis; 2) exogenous Cer induced apoptosis; 3) choline deficiency- and Cer-induced apoptosis both involve a caspase; and 4) inhibition of choline deficiency-induced apoptosis is associated with correction of intracellular Cer levels. However, the source for Cer accumulation is not clear. In most described paradigms of apoptosis, Cer generated from SM hydrolysis mediates apoptosis induced by stimuli such as tumor necrosis factor $\alpha$, ultraviolet radiation, and activation of the CD95 receptor $(8,44)$. Also, an increase in de novo ceramide synthesis may induce apoptosis (44a, 44b). The observation that SM concentration decreased suggests that the Cer accumulation in choline-deficient cells could be derived from sphingomyelin breakdown. In addition to hydrolysis, Cer can be formed via the reversal of the SM synthase path way (SM +DAG $\Rightarrow$ PtdCho+Cer), which is a less-studied possibility for Cer generation. As 

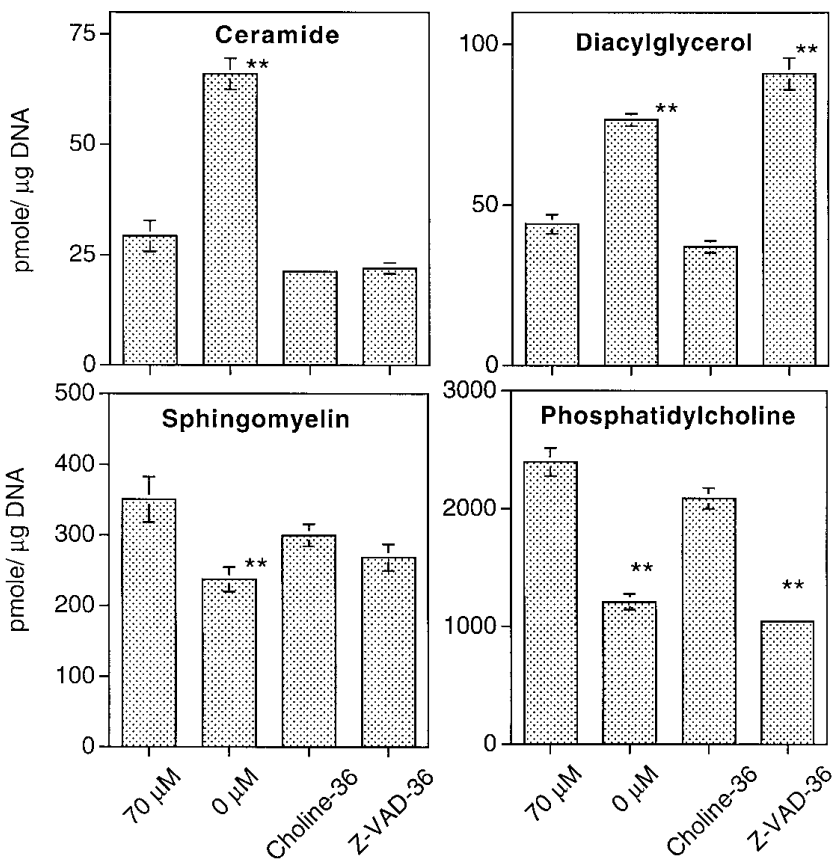

Figure 7. Choline-deprived cells rescued by replacing choline returned their PtdCho, SM, Cer, and DAG concentrations to the levels of control cells, but in cells rescued by adding ZVAD-fmk, only Cer and SM returned to normal. PC12 cells were grown in defined medium without choline for $72 \mathrm{~h}$ as described. Choline or Z-VAD-fmk was added to a final concentration of 70 or $100 \mu \mathrm{M}$, respectively, at $36 \mathrm{~h}$ after initial choline deprivation. Cells were harvested at $72 \mathrm{~h}$. Phospholipids were measured by thin-layer chromatography and a colorimetric assay for phosphorus. Ceramide and diacylglycerol were measured by a radioenzymatic assay. Data represent means $\pm S E, n=4 /$ point, $* * P<0.01$ different from control.

shown in this study, lack of choline moiety creates a situation in which the product (DAG) of SM synthesis increases while the precursor (PtdCho) decreases, which favors the reversal of SM synthase (transfer of the phosphocholine head group of SM to DAG to generate PtdCho). It is also possible that decreased SM and accumulated Cer observed in choline-deficient cells are the result of diminished SM synthesis due to lack of the phosphocholine donor, PtdCho. We are currently investigating the source of Cer accumulation in choline deficiency.

The observation that Z-VAD-fmk, a broad spectrum caspase inhibitor, blocked both choline deficiency- and Cer-induced apoptosis indicates that these forms of apoptosis are mediated by a deathsignaling pathway that involves at least one caspase protease. Our observations agree with the earlier work showing ceramide induces apoptosis in PC12 cells (29) and with reports that caspase-3 (CPP32) is a downstream messenger in the Cer-mediated apoptosis pathway $(30,45,46)$. O ur observation that ZVAD-fmk blocked choline deficiency-induced Cer generation and prevented the drop in SM concentration suggests that a caspaselike activity is upstream of Cer generation. It has been reported that
Cer generation induced by tumor necrosis factor $\alpha$ or Fas activation was suppressed by the caspase inhibitor YVAD-cmk (47).

Apoptosis initiated by exposure to some cytokines, chemotherapeutic agents, or withdrawal of growth factors often reaches commitment stage with in a time course ranging from 4 to $24 \mathrm{~h}$ (48). Unlike the above treatments, placing cells in choline-deficient medium may take some time before intracellular choline pools are depleted and a signal cascade is initiated. Our rescue studies (choline replacement and addition of caspase inhibitor) suggest that cells commit to apoptosis approximately $48 \mathrm{~h}$ after being switched to a choline-devoid medium. This time point coincides with the timing for decrease in PtdCho and an increase in Cer concentrations. We propose that this may be the time that an irreversible step occurs.

In summary, we examined the mechanism by which choline deficiency induces apoptosis by studying the effect of choline deprivation on choline phospholipids and relevant second messengers. We showed that choline deprivation leads to the generation of a death signal, Cer, and also that the death path way involves a caspase protease. There was a critical time period beyond which the choline-deprived cells were committed to death, and this time point coincided with when changes in PtdCho, SM, and Cer were observed. The mechanisms that we identified using this model may help us to explain how dietary choline influences brain development.

This work was supported by a grant from the National Institutes of H ealth (AG09525). C.-L.Y. is supported, in part, by a fellowship from Chinook Group, Inc.

\section{REFERENCES}

1. Steller, H. (1995) Mechanisms and genes of cellular suicide. Science 267, 1445-1449

2. Thompson, C. B. (1995) Apoptosisin the pathogenesis and treatment of disease. Science 267, 1456-1462

3. Kerr, J. F. R., Wyllie, A. H., and Currie, A. R. (1972) Apoptosis: a basic biological phenomenon with wide-ranging implications in tissue kinetics. Br. J. Cancer 26, 239-257

4. Wyllie, A. H . (1987) Cell death. Int. Rev. Cytol. 17 (Suppl.), 755785

5. Arends, M. J., Morris, R. G., and Wyllie, A. H. (1990) Apoptosis. The role of the endonuclease. Am. J. Pathol. 136, 593-608

6. Arends, M. J., and Wyllie, A. H. (1991) Apoptosis mechanisms and role in pathology. Int. Rev. Exp. Pathol. 32, 223-254

7. Yuan, J. (1996) Evolutionary conservation of a genetic pathway of programmed cell death. J. Cell. Biochem. 60, 4-11

8. Hannun, $Y$. (1996) Functions of ceramide in coordinating cellular responses to stress. Science 274, 1855-1859

9. Institute of Medicine, National Academy of Sciences USA. (1998) Dietary reference intakes for folate, thiamin, riboflavin, niacin, vitamin $\mathrm{B}_{12}$, pantothenic acid, biotin, and choline. $\mathrm{Na}$ tional Academy Press, Washington D.C.

10. Zeisel, S. H., and Blusztajn, J. K. (1994) Choline and human nutrition. Annu. Rev. Nutr. 14, 269-296

11. Albright, C. D., Lui, R., Bethea, T. C., da Costa, K.-A., Salganik, R. I., and Zeisel, S. H. (1996) Choline deficiency induces apoptosis in SV40-immortalized CWSV-1 rat hepatocytes in culture. FASEB J. 10, 510-516 
12. Holmes-McNary, M. Q., Loy, R., Mar, M.-H., Albright, C. D., and Zeisel, S. H. (1997) Apoptosis is induced by choline deficiency in fetal brain and in PC12 cells. Dev. Brain Res. 101, 9-16

13. Shin, O.H., Mar, M. H., Albright, C. D., Citarella, M. T., daCosta, K. A., and Zeisel, S. H. (1997) Methyl-group donors cannot prevent apoptotic death of rat hepatocytes induced by choline-deficiency. J. Cell. Biochem. 64, 196-208

14. Zeisel, S. H. (1996) Choline: a nutrient that is involved in the regulation of cell proliferation, cell death, and cell transformation. Adv. Exp. Med. Biol. 399, 131-141

15. Merrill, A. H., and Jones, D. D. (1990) An update of the enzymology and regulation of sphingomyelin metabolism. Biochim. Biophys. Acta 1044, 1-12

16. Spiegel, S., and Merrill, A. J. (1996) Sphingolipid metabolism and cell growth regulation. FASEB J. 10, 1388-1397

17. Exton, J. H. (1994) Phosphatidylcholine breakdown and signal transduction. Biochim. Biophys. Acta 1212, 26-42

18. Meck, W., and Williams, C. (1997) Perinatal choline supplementation increases the threshold for chunking in spatial memory. NeuroReport 8, 3053-3059

19. Meck, W., and Williams, C. (1997) Characterization of the facilitative effects of perinatal choline supplementation on timing and temporal memory. NeuroReport 8, 2831-5

20. Meck, W., and Williams, C. (1997) Simultaneous temporal processing is sensitive to prenatal choline availability in mature and aged rats. NeuroReport 8, 3045-51

21. Loy, R., Heyer, D., Williams, C. L., and Meck, W. H. (1991) Choline-induced spatial memory facilitation correlates with altered distribution and morphology of septal neurons. Adv. Exp. Med. Biol. 295, 373-382

22. Meck, W. H., Smith, R. A., and Williams, C. L. (1988) Pre- and postnatal choline supplementation produces long-term facilitation of spatial memory. Dev. Psychobiol. 21, 339-353

23. Wyllie, A. H. (1980) Glucocorticoid-induced thymocyte apoptosis is associated with endogenous endonuclease activation. $\mathrm{Na}$ ture (London) 284, 555-556

24. Labarca, C., and Paigen, K. (1980) A simple, rapid and sensitive DNA assay procedure. Anal. Biochem 102, 344-352

25. Bligh, E. G., and Dyer, W. J. ( 1959) A rapid method of total lipid extraction and purification. Can. J. Biochem. Physiol. 37, 911917

26. Svanborg, A., and Svennerholm, L. (1961) Plasma total lipids, cholesterol, triglycerides, phospholipids and free fatty acids in a healthy Scandinavian population. Acta Med. Scand. 169, 43-49

27. Pomfret, E. A., daCosta, K., Schurman, L. L., and Zeisel, S. H. (1989) Measurement of choline and choline metabolite concentrations using high-pressure liquid chromatography and gas chromatography-mass spectrometry. Anal. Biochem. 180, 85-90

28. Preiss, J., Loomis, C. R., Bishop, W. R., Stein, R., Niedel, J. E., and Bell, R. M. (1986) Quantitative measurement of sn-1,2-diacylglycerols present in platelets, hepatocytes, and ras- and sistransformed normal rat kidney cells. J. Biol. Chem. 261, 85978600

29. Hartfield, P., Mayne, G., and Murray, A. (1997) Ceramide induces apoptosis in PC12 cells. FEBS Lett. 401, 148-152

30. Yoshimura, S., Banno, Y., N akashima, S., Takenaka, K., Sakai, H ., Nishimura, Y., Sakai, N., Shimizu, S., Eguchi, Y., Tsujimoto, Y., and Nozawa, Y. (1998) Ceramide formation leads to caspase-3 activation during hypoxic PC12 cell death - inhibitory effects of $\mathrm{BCl} 2$ on ceramide formation and caspase-3 activation. J. Biol. Chem. 273, 6921-7

31. Pyapali, G., Turner, D., Williams, C., Meck, W., and Swartzwelder, H. S. (1998) Prenatal choline supplementation decreases the threshold for induction of long-term potentiation in young adult rats. J. Neurophysiol. 79, 1790-1796

32. Meck, W. H., Smith, R. A., and Williams, C. L. (1989) Organizational changes in cholinergic activity and enhanced visuospatial memory as a function of choline administered prenatally or postnatally or both. Behav. Neurosci. 103, 1234-1241

33. Jackowski, S. (1994) Coordination of membrane phospholipid synthesis with the cell cycle. J. Biol. Chem. 269, 3858-3867
34. Boggs, K., Rock, C., and Jackowski, S. (1995) Lysophosphatidylcholine and 1-0-octadecyl-2-0-methyl-rac-glycero-3-phosphocholine inhibit the CDP-choline path way of phosphatidylcholine synthesis at the CTP:phosphocholine cytidylyltransferase step. J. Biol. Chem. 270, 7757-7764

35. Boggs, K. P., Rock, C. O., and Jackowski, S. (1995) Lysophosphatidylcholine attenuates the cytotoxic effects of the antineoplastic phospholipid 1-0-octadecyl-2-0-methyl-rac-glycero-3phosphocholine. J. Biol. Chem. 270, 11612-11618

36. Zeisel, S. H., Albright, C. D., Shin, O.-K., Mar, M.-H., Salganik, R. I., and da Costa, K.-A. (1997) Choline deficiency selects for resistance to p53-independent apoptosis and causestumorigenic transformation of rat hepatocytes. Carcinogenesis 18, 731-738

37. da Costa, K.-A., Garner, S. C., Chang, J., and Zeisel, S. H. (1995) Effects of prolonged ( 1 year) choline deficiency and subsequent refeeding of choline on 1,2,-sn-diradylglycerol, fatty acids and protein kinase $C$ in rat liver. Carcinogenesis 16, 327-334

38. Jarvis, W. D., Fornari, F. A., Jr., Browning, J. L., Gewirtz, D. A., Kolesnick, R. N., and Grant, S. (1994) Attenuation of ceramideinduced apoptosis by diglyceride in human myeloid leukemia cells. J. Biol. Chem. 269, 31685-31692

39. Tepper, C. G., Jayadev, S., Liu, B., Bielawska, A., Wolff, R., Yonchara, A., H annun, Y. A., and Seldin, M. F. (1995) Role for ceramide as an endogenous mediator of Fas-induced cytotoxicity. Proc. Natl. Acad. Sci. USA 92, 8443-8447

40. Kolesnick, R. N. (1987) 1,2-Diacylglycerols but not phorbol esters stimulate sphingomyelin hydrolysis in $\mathrm{GH} 3$ pituitary cells. J. Biol. Chem. 262, 16759-16762

41. Schutze, S., Potthoff, K., Machleidt, T., Berkovic, D., Wiegmann, K., andKronke, M. (1992) TNF activates NF-kappa B by phosphatidylcholine-specific phospholipase C-induced 'acidic' sphingomyelin breakdown. Cell 71, 765-776

42. Cifone, M., Roncaioli, P., De Maria, R., Camarda, G., Santoni, A., Ruberti, G., and Testi, R. (1995) Multiple pathways originate at the Fas/ APO-1 (CD95) receptor: sequential involvement of phosphatidylcholine-specific phospholipase $C$ and acidic sphingomyelinase in the propagation of the apoptotic signal. EMBO J. 14, 5859-5868

43. da Costa, K., Cochary, E. F., Blusztajn, J. K., Garner, S. C., and Zeisel, S. H. (1993) Accumulation of 1,2-sn-diradylglycerol with increased membrane-associated protein kinase $C$ may be the mechanism for spontaneous hepatocarcinogenesis in cholinedeficient rats. J. Biol. Chem. 268, 2100-2105

44. Verheij, M., Bose, R., Lin, X., Yao, B., Jarvis, W. D., Grant, S., Birrer, M. J., Szabo, E., Zon, L. I., Kyriakis, J. M., H aimovitzFriedman, A., Fuks, Z., and Kolesnick, R. (1996) Requirement for ceramide-initiated SAPK/JNK signalling in stress-induced apoptosis. Nature (London) 380, 75-79

44a. Paumen, M. Ishida, Y., Muramatsu, M., Yamamoto, M., and Honjo, T. (1997) Inhibition of carnitine palmitoyltransferase I augments sphingolipid synthesis and palmitate-induced apoptosis. J. Biol. Chem. 272, 3324-3329

44b. Shimabukuro, M., Zhou, Y. Levi, M., and Unger, R. (1998) Fatty acid-induced beta cell apoptosis: a link between obesity and diabetes. Proc. Natl. Acad. Sci. USA 95; 2498-2502

45. Smyth, M., Perry, D., Zhang, J., Poirier, G., H annun, Y., and Obeid, L. (1996) prlCE: a downstream target for ceramide-induced apoptosis and for the inhibitory action of Bcl-2. Biochem. J. 316, 25-28

46. Mizushima, N., Koike, R., Kohsaka, H., Kushi, Y., H anda, S., Yagita, H., and Miyasaka, N. (1996) Ceramide induces apoptosis via CPP32 activation. FEBS Lett. 395, 267-271

47. Gamard, C., Dbaibo, G., Liu, B., Obeid, L., and Hannun, Y. (1997) Selective involvement of ceramide in cytokine-induced apoptosis. J. Biol. Chem. 272, 16474-1681

48. Potten, C. (1996) What is an apoptotic under measuring? A commentary. Br. J. Cancer 74, 1743-1748

Received for publication M arch 9, 1998. Revised for publication August 27, 1998. 